Article

\title{
Time Course Exo-Metabolomic Profiling in the Green Marine Macroalga Ulva (Chlorophyta) for Identification of Growth Phase-Dependent Biomarkers
}

\author{
Taghreed Alsufyani ${ }^{\dagger}$, Anne Weiss and Thomas Wichard * \\ Institute for Inorganic and Analytical Chemistry, Jena School for Microbial Communication, Friedrich Schiller \\ University Jena, Jena 07743, Germany; taghreed.alsufyani@gmail.com (T.A.); Anne.Weiss@uni-jena.de (A.W.) \\ * Correspondence: Thomas.Wichard@uni-jena.de; Tel.: +49-3641-948-184 \\ † Current address: Algal Research Laboratory, Chemistry Department, Faculty of Science, Taif University, \\ Taif 21431, Saudi Arabia.
}

Academic Editor: Paul Long

Received: 28 August 2016; Accepted: 3 January 2017; Published: 10 January 2017

\begin{abstract}
The marine green macroalga Ulva (Chlorophyta) lives in a mutualistic symbiosis with bacteria that influence growth, development, and morphogenesis. We surveyed changes in Ulva's chemosphere, which was defined as a space where organisms interact with each other via compounds, such as infochemicals, nutrients, morphogens, and defense compounds. Thereby, Ulva mutabilis cooperates with bacteria, in particular, Roseovarius sp. strain MS2 and Maribacter sp. strain MS6 (formerly identified as Roseobacter sp. strain MS2 and Cytophaga sp. strain MS6). Without this accompanying microbial flora, $U$. mutabilis forms only callus-like colonies. However, upon addition of the two bacteria species, in effect forming a tripartite community, morphogenesis can be completely restored. Under this strictly standardized condition, bioactive and eco-physiologically-relevant marine natural products can be discovered. Solid phase extracted waterborne metabolites were analyzed using a metabolomics platform, facilitating gas chromatography-mass spectrometry (GC-MS) and liquid chromatography-mass spectrometry (LC-MS) analysis, combined with the necessary acquisition of biological metadata. Multivariate statistics of the GC-MS and LC-MS data revealed strong differences between Ulva's growth phases, as well as between the axenic Ulva cultures and the tripartite community. Waterborne biomarkers, including glycerol, were identified as potential indicators for algal carbon source and bacterial-algal interactions. Furthermore, it was demonstrated that $U$. mutabilis releases glycerol that can be utilized for growth by Roseovarius sp. MS2.
\end{abstract}

Keywords: axenic culture; bioreactors; chemosphere; cross-kingdom cross-talk; Maribacter; metabolite profiling; Roseovarius; Ulva

\section{Introduction}

Interactions between the marine macroalga Ulva and its associated bacteria impact directly on the algal morphology and physiology of both partners. Those interactions supposedly change the chemical composition of their environment, and, finally, shape the bacterial diversity of the biocoenose $[1,2]$. Metabolites released into the environment are considered to "act as spoken language, broadcasting signals from the genetic architecture and the environment" [3,4]. Metabolomics can help in providing a functional understanding of the physiological state of an organism or symbiotic interactions. This is particularly intriguing in the light of the exo-metabolome, which is defined by metabolites secreted into the environment by one or more organisms. Thus, the organisms form their chemosphere, interact with each other via compounds, and recruit their nutrients [5]. A non-targeted metabolomics-based approach was 
used to characterize the entire chemosphere of the tripartite community of Ulva and two associated bacteria in contrast to a traditional bioassay-guided fractionation approach that focuses on single molecules.

There is increasing evidence revealing cell-to-cell communication and interactions across the prokaryote-eukaryote boundary, particularly between marine bacteria and macroalgae [6]. This inter-kingdom communication is not only limited to the exchange of macronutrients, but also includes low molecular-weight infochemicals and vitamins [6]. Joint and coworkers [7] demonstrated, for example, that bacterial quorum-sensing signals, such as acyl-homoserine lactones, can serve as settlement cues for germ cells (i.e., zoids) of the marine green alga Ulva. These cues might direct the zoids to the respective bacterial biofilms, releasing, for instance, (additional) morphogenetic compounds (morphogens) [8]. Indeed, specific bacteria isolated from the algal surface promote growth and cell differentiation and, finally, induce algal morphogenesis via diffusible morphogenetic compounds [8]. Under axenic conditions (bacteria-free), slow-growing aberrant phenotypes, which look like calluses, have been observed in Ulva and particularly studied in U. mutabilis [8-10] (Figure 1A). Axenic cultures of Ulva have been shown to form a stable symbiotic tripartite community in the presence of the morphogenesis-inducing bacteria, Roseobacter sp. strain MS2 and Cytophaga sp. strain MS6, both isolated from U. mutabilis [9] (recently reclassified as Roseovarius sp. and Maribacter sp., respectively [11]). In the presence of these two bacteria, algal morphogenesis is completely recovered, mediated through bacterial morphogens [9].

A

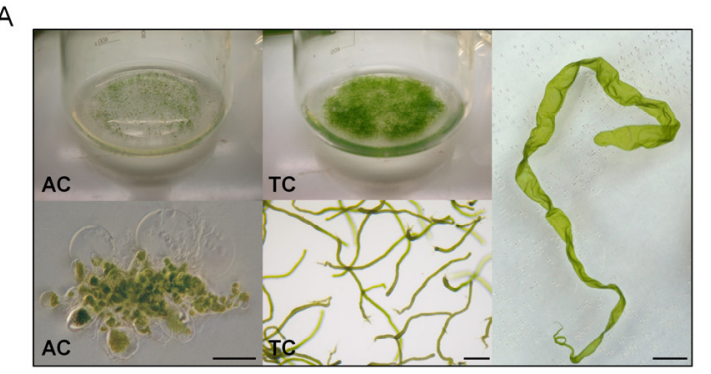

C

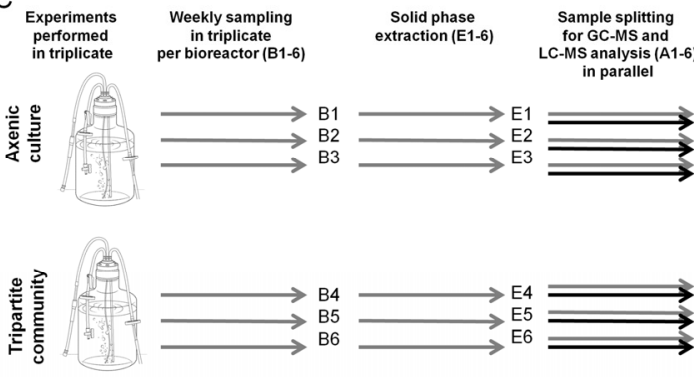

$B$

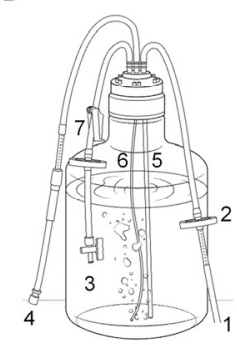

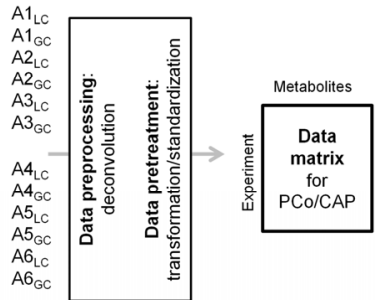

Figure 1. (A) Representative images of Ulva mutabilis (morphotype "slender") are shown. Left: A fiveweek-old axenic culture (AC) with its aberrant morphotype and unusual cell wall protrusions (scale bar $=100 \mu \mathrm{m}$ ); center: Tripartite community (TC) of young germlings and the two bacterial strains Roseovarius sp. MS2 and Maribacter sp. MS6 with normal algal development (scale bar $=100 \mu \mathrm{m}$ ); and right: A mature specimen of $U$. mutabilis (scale bar $=1 \mathrm{~cm}$ ); (B) Drawing of the $25 \mathrm{~L}$ bioreactor used for cultivation of $U$. mutabilis: (1) air inlet; (2) sterile HEPA-Vent $(\varnothing=50 \mathrm{~mm}$, Whatman) filter; (3) air outlet; (4) sampling outlet; (5) bubbling tube (Duran glass, $\varnothing=4 \mathrm{~mm}$ ); (6) sampling tube (Teflon, $\varnothing 1 \mathrm{~mm}$ ); and (7) hose clamp to control the sampling flow; (C) Experimental design: Three bioreactors were inoculated per treatment. Samples were taken from each bioreactor in triplicate for solid phase extraction (SPE). Each extract was then divided in half for gas chromatography-mass spectrometry (GC-MS) and ultra high performance liquid chromatography-mass spectrometry (UHPLC-MS) analyses. Three injections of each sample were used for UHPLC analysis. Upon identification of pairs of retention time and $m / z$, the data matrix obtained was transformed and standardized before multivariate analysis (PCoA/CAP) was conducted. 
U. mutabilis was originally collected by Føyn on the south coast of Portugal in 1952 [12,13]. From that time, the isolates, which are still in culture, have been used intensively as a convenient model for studying algal development, mainly using classic methods [14]; however, recent advances in chemical ecology and algal genetics have reinforced molecular investigations [15-17].

$U$. mutabilis possesses several key traits important for controlled growth and cultivation. An analysis of the vegetative cell cycle, using radioactive labeling with ${ }^{14} \mathrm{C}$-uracil, confirmed that the cell cycles are synchronous and govern circadian rhythm [18]. Additionally, blade cells of $U$. mutabilis excrete sporulation inhibitors into cell walls and the environment. These compounds, a glycoprotein and several small molecular weight compounds, are essential in maintaining the vegetative state. However, it should be noted that the gametogenesis of mature blades can be artificially induced by mincing the thallus into single mono-layered fragments and by washing-out of the sporulation inhibitors [18-20]. As these inhibitors can only be assessed by laborious bioassays, the identification of new growth phase biomarkers would allow regulative checkpoints in the life cycle of Ulva to be established. This could also prove valuable for the monitoring of aquacultures, as blade cells spontaneously differentiate into gametangia when they age [18].

In this study, the chemosphere produced by a synthetic microbiome in its most simplistic variation, the tripartite community consisting of $U$. mutabilis, Roseovarius sp. strain MS2, and Maribacter sp. strain MS6, was studied under laboratory conditions (Figure 1B). We investigated the composition of the bacterial and algal metabolites released during algal growth under standardized conditions, and compared the chemosphere between the axenic algal culture and the tripartite community using an exo-metabolomic approach (Figure 1C).

\section{Results and Discussion}

\subsection{Experimental Design and Biological Metadata}

Waterborne metabolites were isolated from the culture supernatant during Ulva's growth on a weekly basis using solid phase extraction (SPE) and, subsequently, analyzed by gas chromatography (GC) and ultra-high pressure liquid chromatography (UHPLC) coupled to a time-of-flight mass spectrometer (ToF-MS). In parallel, biological metadata including (i) nutrients; (ii) sporulation- and swarming inhibitors; and (iii) algal/bacteria growth rates were determined (Figure 1). The following experimental metadata were recorded from Ulva cultures in bioreactors: (i) the growth of U. mutabilis; (ii) the depletion of nitrate and phosphate in growth media; (iii) the changes in the algal life cycle; (iv) the status of the inducibility of Ulva's gametogenesis; and (v) the axenicity of the cultures, as well as the associated microbiome of the tripartite community.

\subsubsection{Assessment of Algal Growth and the Bacterial Community}

U. mutabilis developed a normal morphology in the tripartite community, with apparent growth one week after inoculation (Figure 1A). Longitudinal growth was recorded until the end of the experiment, when the average length of a thallus was about $25 \mathrm{~cm}$ (Day 56 after inoculation, Figure 2A). In fact, algal biomass continuously increased, as aerification of the cultures prevented algal self-shading. As previously described [9], U. mutabilis did not grow properly under axenic conditions (Figure 2B) and formed dark green callus-like colonies with typical protrusions of the cell walls (Figure 1A).

Owing to the tubular and cylindrical nature of the thallus of $U$. mutabilis (slender), the length was an appropriate proxy for growth measurements. Light green thalli were observed from Day 0 to Day 14. By Day 14, they had changed to olive-green. The first brownish green and colorless thalli appeared from Day 28 onwards, indicating spontaneously induced gametogenesis.

In order to assess the bacteria within the tripartite community over time, they were routinely identified by amplifying the $16 \mathrm{~S}$ rRNA gene using PCR (Figure 2C). It was important to use established primers, which cover a wide range of marine bacteria [21,22], in order to detect potential bacterial contaminants in the bioreactor cultures. The absence of the amplicons proved the axenicity throughout 
the complete period of cultivation under axenic conditions (Figure 2C). At the end of the experiment (Day 49), denaturing gradient gel electrophoresis (DGGE) analysis revealed that only the inoculated strains, MS2 and MS6, were identified in samples collected from the tripartite community (Figure 2D).
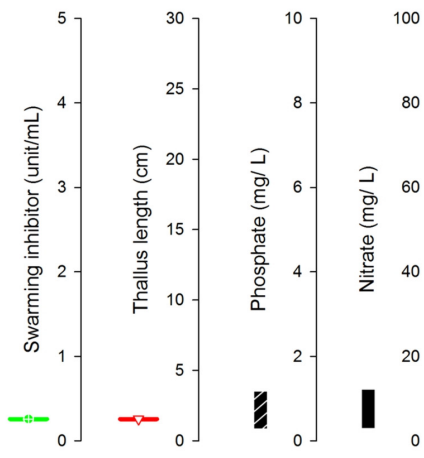

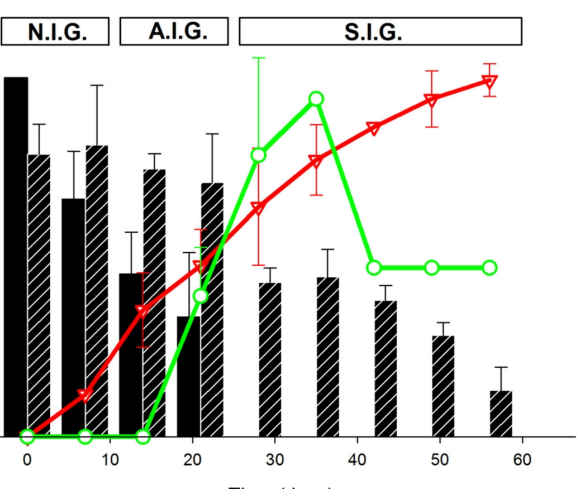

B
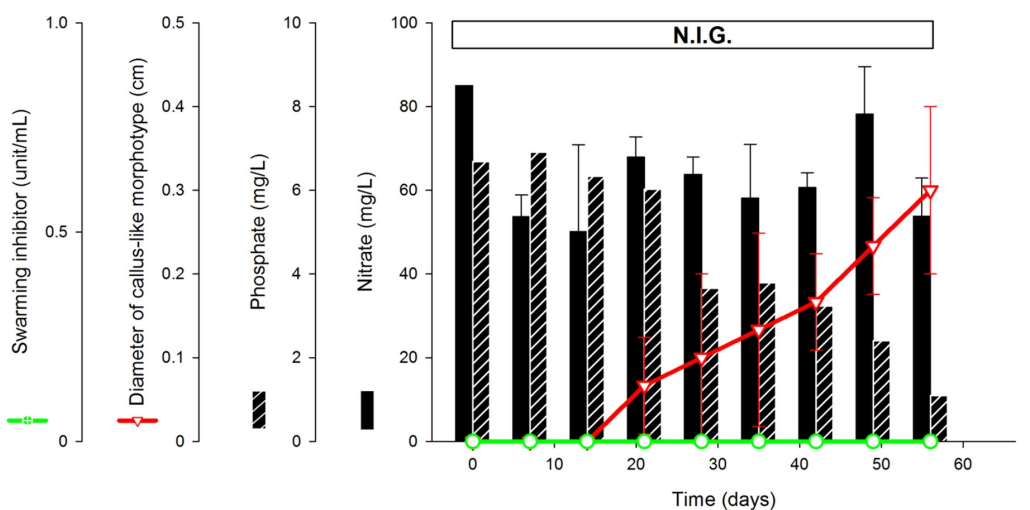

C

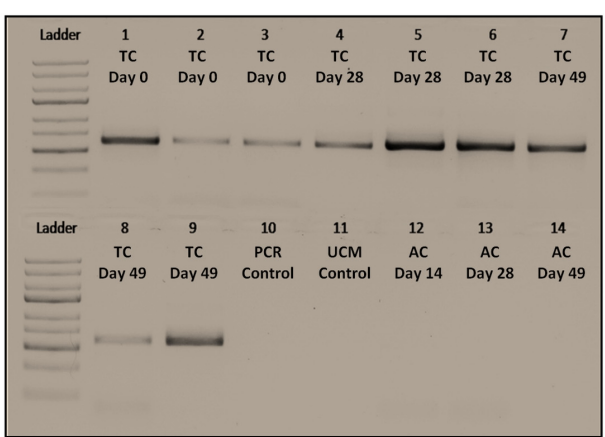

D

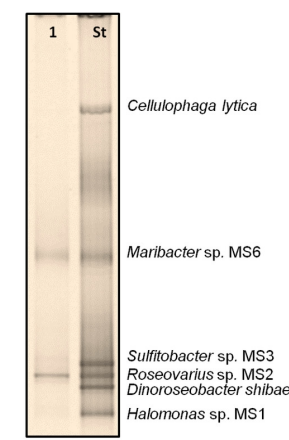

Figure 2. (A) Diagram summarizing all biotic and abiotic data (i.e., biological metadata) for Ulva's tripartite community (TC), which have been collected from the onset of the algal culture (Day 0) until the mature specimen of $U$. mutabilis was ready for spontaneous gametogenesis, terminating the cultivation. The life cycle of $U$. mutabilis status was categorized according to the inducibility of the gametogenesis: non-inducible gametogenesis (N.I.G.), artificially inducible status (A.I.G.), spontaneously inducible status (S.I.G.) (mean values $\pm \mathrm{SD}(n=3)$ ); (B) The same as (A), but $U$. mutabilis was grown under axenic conditions (AC); (C) Axenicity of the Ulva culture medium and presence of bacteria was proven by PCR of the 16S rRNA gene. An agarose gel is shown. Lanes 1-9: U. mutabilis inoculated with bacteria (TC) tested in three bioreactors on days 0 (1-3), 28 (4-6) and 49 (7-9); Lane 10: PCR-negative control; Lane 11: Control of Ulva culture medium (UCM) without Ulva and bacteria; Lanes 12-14: Axenic cultures (AC) tested on days 14 (12), 28 (13) and 49 (14); (D) Denaturing gradient gel electrophoresis analysis of PCR-amplified fragments of the bacterial 16S rRNA genes in the tripartite community on Day 49 (Lane 1) has been amplified to compare it with a mix of DNA standards derived from reference bacteria (Lane St). 


\subsubsection{Nutrient Depletion in Ulva Culture Medium (UCM)}

U. mutabilis completed the life cycle, starting from germlings and finally forming thalli, under conditions shown in Figure 2A, i.e., when nutrient concentrations changed and nitrate was completely depleted. As the medium did not need to be renewed, the dynamic changes of the bacterial and algal exudates could be assessed during the whole algal life cycle.

Upon inoculation, the concentration of nitrate decreased within one week $(p<0.05)$. Nitrate was then continuously taken up by Ulva until Day 28 (Figure 2A); nitrite was not detected. The phosphate concentration decreased steadily to almost half of the initial concentration $(3.5 \mathrm{mg} / \mathrm{L})$ within the tripartite community, and remained at this level until the end of the experiment without significant changes (Figure 2A). The weekly utilization rates (UR) indicated that nitrate was consumed faster $\left(\mathrm{UR}_{\text {Nitrate }}=33 \%\right)$ than phosphate $\left(\mathrm{UR}_{\text {Phosphate }}=5 \%\right)$ in the tripartite community. In the fourth week post inoculation, the complete depletion of nitrate was determined (i.e., $\mathrm{UR}_{\text {Nitrate }}=100 \%$ ) and phosphate was then taken up $\left(\mathrm{UR}_{\text {Phosphate }}=45 \%\right)$.

The only significant depletion of the nutrients in axenic cultures was recorded for nitrate $(p<0.05)$ one week post inoculation, when the initial concentration, i.e., $85 \mathrm{mg} / \mathrm{L}$, dropped to $53 \mathrm{mg} / \mathrm{L}$ (Figure 2B) with $\mathrm{UR}_{\text {Nitrate }}=37 \%$ (Figure $2 \mathrm{~B}$ ). Both the axenic culture and the tripartite community utilized nitrate at similar rates (33\% and 37\%, respectively) during the lag phase. Ulva is, thus, able to accumulate excess cellular nitrate for continuous growth, as was previously shown [23].

\subsubsection{Inducibility of Gametogenesis and Production of the Swarming Inhibitor}

Spontaneous gametogenesis was not observed until four weeks, or even later, but gametogenesis could be artificially induced after two to three weeks by fragmentation of the thallus, washing, and suspension in fresh medium, which indicated the presence of sporulation and swarming inhibitors [18-20,24]. Discharged gametes were observed on Day 35. About 15\% of the entire population had already run through the spontaneous gametogenesis by Day 42, and germlings were, hence, found one week later in all bioreactors of the tripartite community.

Previous studies have reported that the swarming inhibitor (SWI) was released into the growth medium during gametogenesis, most probably for the synchronization of gamete discharge [18,24] and can, thus, be used as a proxy for the status of Ulva's life cycle. Indeed, the activity of the SWI was determined in the growth medium of the tripartite community on Day $21(1.7 \mathrm{units} / \mathrm{mL})$. Afterward, the activity increased significantly $(p<0.05)$ and peaked on Day 35 with 3.3 and 4 units $/ \mathrm{mL}$, respectively. After 35 days, the activity dropped to 2 units $/ \mathrm{mL}(p<0.05)$, and remained constant without significant change until the end of this experiment. No SWI activity could be detected in the axenic cultures (Figure 2B), as those algae do not run through gametogenesis.

Based on the inducibility of gametogenesis and the determination of the SWI activity, three phases of growth were defined in the tripartite community of $U$. mutabilis: (i) "Non-inducible gametogenesis" (N.I.G.: Day 7); (ii) "artificially inducible gametogenesis" (A.I.G.: days 14-21); and (iii) "spontaneously inducible gametogenesis" (S.I.G.: days 28-49) (Figure 2A). All axenic cultures were categorized in the phase N.I.G. (Figure 2B).

We then hypothesized that the growth stage (i.e., groups N.I.G., A.I.G., and S.I.G.) of Ulva at any particular time point can be revealed by the variability and composition of the metabolite profile of the chemosphere. To identify the relationships between growth stages and the chemosphere of the tripartite community, statistical analyses of the metabolite profiles using principal coordinate analysis followed by a canonical discriminant analysis with the a priori groups N.I.G., A.I.G., and S.I.G. were performed.

\subsection{Data Analysis and Identification of Biomarkers in the Chemosphere via GC-MS}

Using the Automated Mass spectral Deconvolution and Identification System (AMDIS) and the Metabolomics Ion-based Data Extraction Algorithm (MET-IDEA), the analysis of the GC-chromatograms 
revealed a total of about 400 waterborne compounds detected within the tripartite community, where growth and development were observed. Canonical correlation analyses can give exact probability values and demonstrate the differences in biomarkers that reveal the changes in the exo-metabolome during Ulva's life cycle, in comparison with the tripartite community and axenic growth of Ulva (Figure 3). Whereas differences between samples in multivariate space (PCo) were not directly apparent in the unconstrained ordination (Figure S1A), they were clearly uncovered and displayed by canonical analysis of principle coordinates (CAP) analysis (Figure 3A) using the states of gametogenesis, N.I.G., A.I.G. and S.I.G., as three a priori groups. Importantly, samples of the axenic cultures were combined over the entire experimental period (49 days), including the lag phase of the tripartite community (N.I.G.).

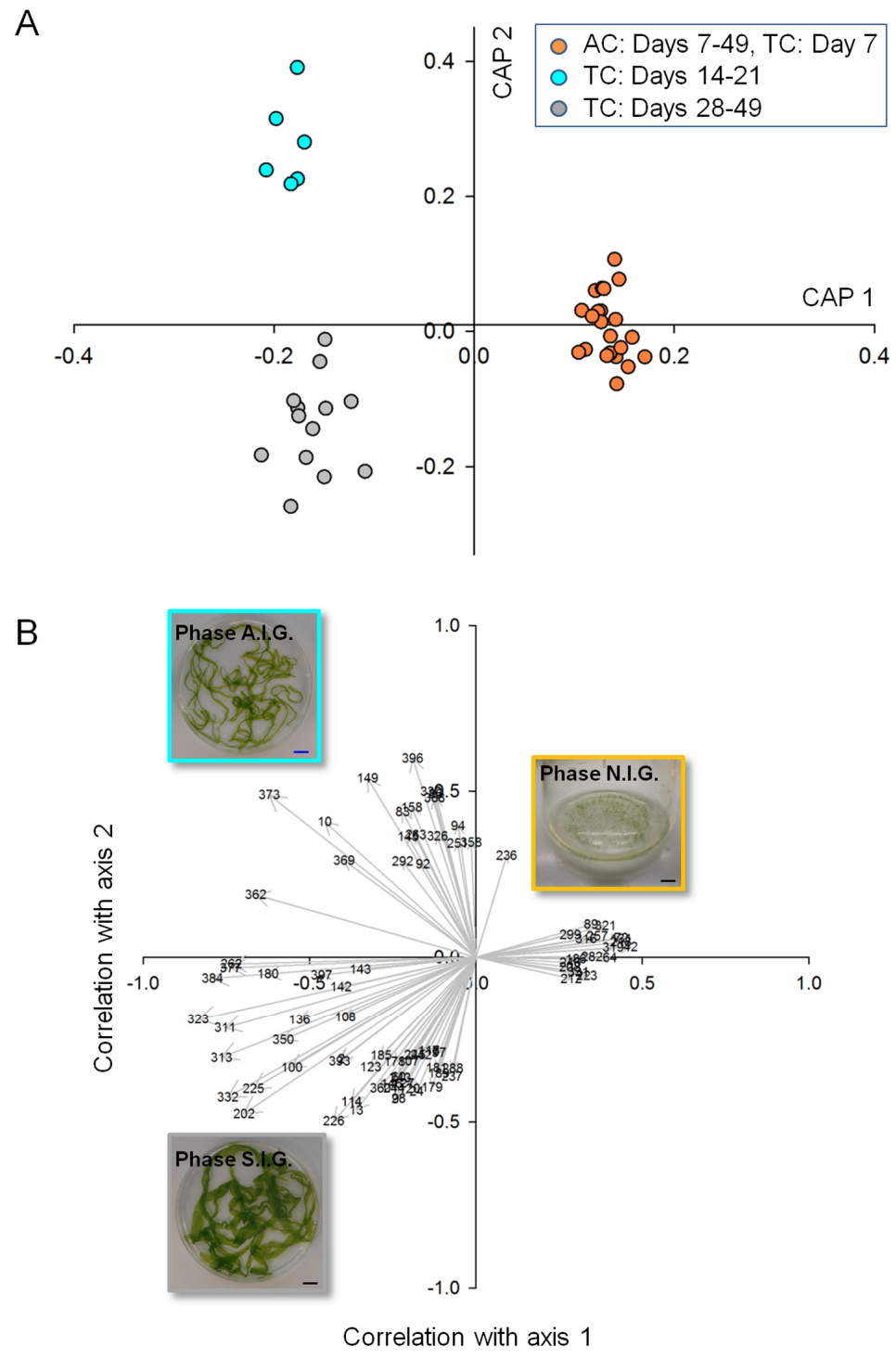

Figure 3. Multivariate data analysis of the exo-metabolome of Ulva mutabilis within the tripartite community (TC) and grown under axenic conditions (AC) after GC-MS measurements of 43 samples: (A) the first two canonical axes of the canonical analysis of principle coordinates (CAP) analysis are plotted. CAP analysis demonstrates the separation based on the states of gametogenesis along with the growth phases of $U$. mutabilis: non-inducible gametogenesis (N.I.G., orange), artificially inducible status (A.I.G., turquoise) and spontaneously inducible status (S.I.G., light gray); (B) Scaled vectors of the metabolites (ID numbers) were significant $(|r|>0.3)$ for the separation of the groups. The numbers refer to the metabolites in the heat map (Figure 4). Inserts show images of Ulva's growth during the three phases, N.I.G., A.I.G., and S.I.G., selected as a priori groups for CAP analysis (bar $=1 \mathrm{~cm})$. 
CAP analyses revealed that metabolite profiles significantly differed between the three growth phases (Eigenvalues: 0.9512 for axis 1 and 0.9200 for axis 2). The cross validation between the a priori groups resulted in $2 \%$ misclassification using the "leave-one-out" allocation procedure and indicates significant differences.

Correlation coefficients between each of the samples and the canonical axes were calculated by CAP. If $|r|>0.3$ was chosen as a cutoff point for a correlation coefficient, which was large enough to be considered as an essential biomarker, it turned out that only the first two canonical axes had any correlation that exceeded the value in the absolute (see also Section 3).

In order to interpret which metabolites were essential for the separation, correlations with one of the two constrained canonical axes were examined (Figure 3B). The heat map, derived from the relative intensities of the 27 metabolites (including six unidentified compounds), showed that the change in their production and release correlated with the transition through the three growth phases (Figure 4). Of the 21 identified metabolites several, including glycerol, organic acids, amino acids, and 2,4,6-tribromophenol (TBP), were assessed in their putative chemical-ecological context within the Ulva-bacteria chemosphere (see Section 2.4).

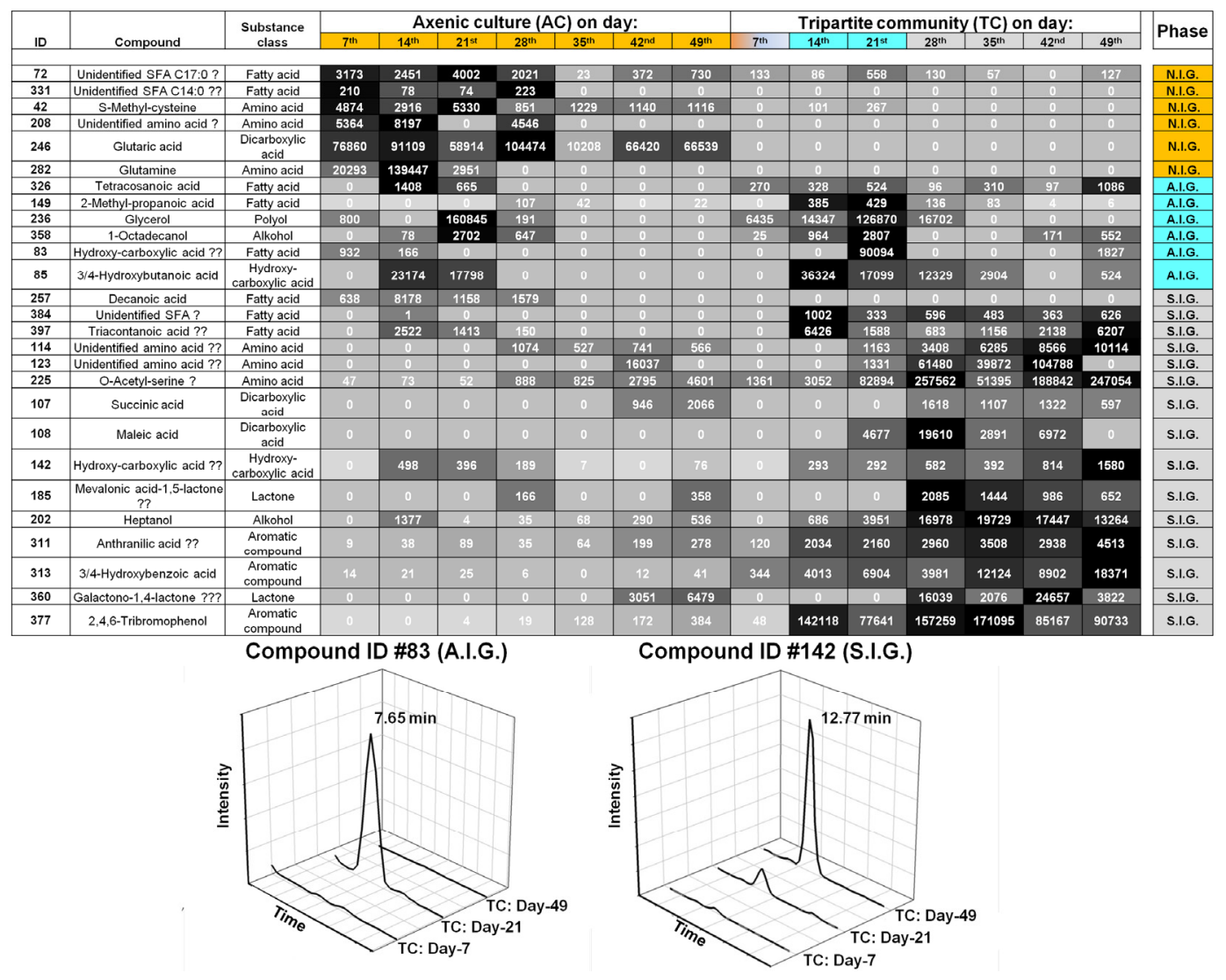

Figure 4. Heat map of the intensities of exo-metabolites, which were correlated with the CAP axis $(|r|>0.3)$ and contributed to the classification of the growth phases (N.I.G., A.I.G., and S.I.G), based on GC-MS analysis. Metabolites were extracted from Ulva growth medium of the tripartite community (TC) or axenic culture (AC). Relative intensities were given in the range from 0 to 250,000. Smaller values were represented by light gray and higher values by dark grey/black boxes. Metabolites marked with a "?" had reverse match between 800 and 700, and marked with "??" a reverse match of below 700. The color code refers to the three states of the gametogenesis: non-inducible gametogenesis (N.I.G., orange), artificially inducible status (A.I.G., turquoise) and spontaneously inducible status (S.I.G., light gray). Representative ion trace chromatograms of the two biomarkers, ID \#83 and ID \#142, for phases A.I.G. and S.I.G. over the time course, are presented. 


\subsection{Data Analysis and Identification of Important Biomarkers in the Chemosphere via LC-MS Analysis}

The detection of unknown metabolites is very typical for data obtained in LC-MS metabolomics [25]. Therefore, our aim was to identify those biomarkers that describe the different growth phases of the Ulva-bacterial tripartite community, based on its waterborne substances and to classify these as "known unknowns" [26] (Figures 5 and 6). Overall, the LC-MS analyses of the exo-metabolome supported the stages categorized by GC-MS analyses. Again, whereas real group differences in multivariate space (PCo) were not apparent in the unconstrained ordination (Figure S1B), they were uncovered and displayed by the CAP (Eigenvalues: 0.9547 for axis 1 and 0.9115 for axis 2, Figure 5B), as seen in previous studies [27]. The cross validation between the a priori groups resulted in $4.5 \%$ misclassification using the "leave-one-out" allocation procedure. For better illustration, vectors of biomarkers were plotted according to their retention times (Figure 5B) indicating changes in the pattern of polarity of the waterborne metabolites. Hydrophilic waterborne metabolites (biomarkers such as \#18 ( $\mathrm{m} / \mathrm{z}$ 127), \#125 ( $\mathrm{m} / \mathrm{z}$ 186), \#293 (m/z 218), \#386 ( $\mathrm{m} / \mathrm{z} 247), \# 391(\mathrm{~m} / \mathrm{z} 249)$, $\# 539(\mathrm{~m} / \mathrm{z} 281)$ and \#658 ( $\mathrm{m} / \mathrm{z} 305)$, Figure 6$)$ contributed significantly to the characterization of the growth phase N.I.G. and axenic culture conditions, whereas waterborne metabolites, which have been retained longer on a C18 column, due to their higher lipophilic nature, act as significant biomarkers for the growth phase S.I.G. of the tripartite community (biomarkers: \#70 $(\mathrm{m} / z$ 173), \#621 ( $m / z$ 297), \#750 ( $m / z 327), \# 950(m / z 383)$ and \#962 ( $m / z ~ 387)$, Figure 6). Morphogenetic compounds, such as thallusin and bacterial quorum-sensing compounds typically associated with communication between Ulva and bacteria [7,8], could not be detected. This is likely due to their exceedingly low concentrations; such compounds tend to be highly potent and will elicit a response even at concentrations below the MS detection limit. The heat map depicted for the first time the dynamic changes of the waterborne compounds, made possible by the fact that the growth medium did not need to be changed during the Ulva's haploid stages of life cycle (i.e., from gametes as seed stock until a thallus harboring mature gametangia) (Figures 5 and 6 ). The transition phase, A.I.G., characterized by biomarkers \#371 ( $\mathrm{m} / \mathrm{z} 243), \# 446(\mathrm{~m} / \mathrm{z} 262), \# 485(\mathrm{~m} / \mathrm{z} 271), \# 618(\mathrm{~m} / \mathrm{z} 297)$, $\# 675(\mathrm{~m} / z$ 308), \#937 ( $\mathrm{m} / z$ 378) and \#1118 $(\mathrm{m} / \mathrm{z} 443)$, was of particular interest, as these correlated well with the phase when gametogenesis could be artificially induced (A.I.G.) for the first time in Ulva's life cycle.

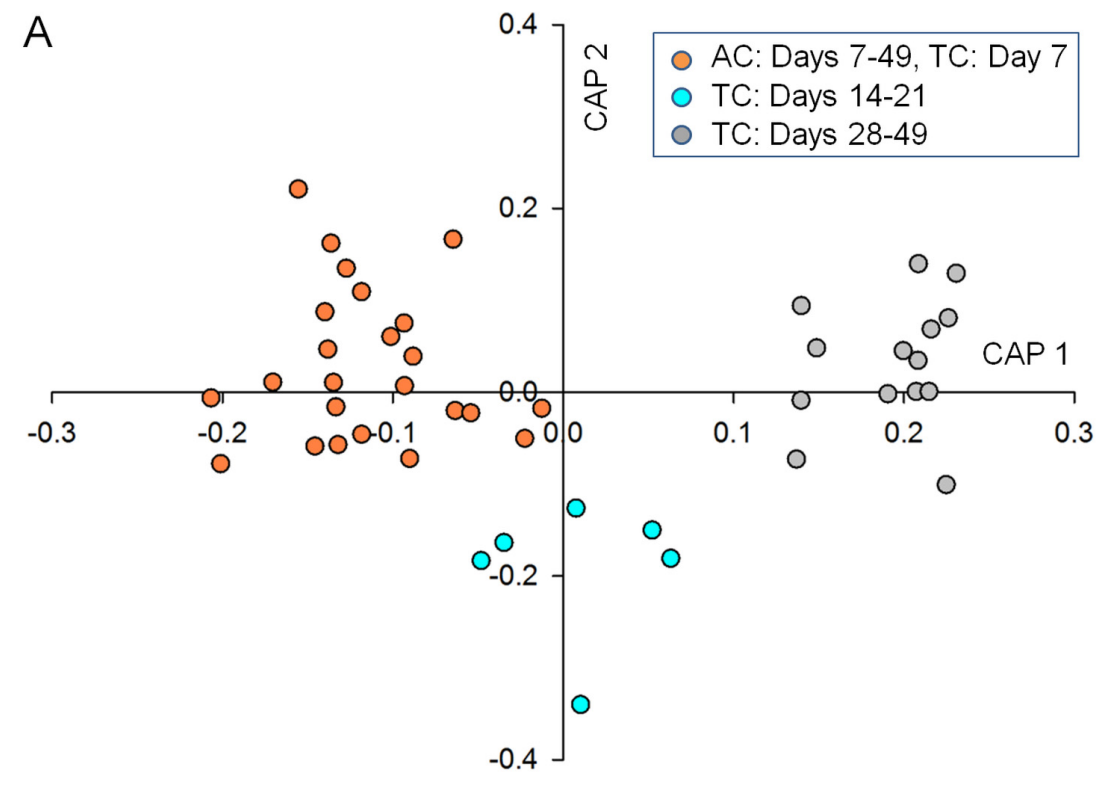

Figure 5. Cont. 


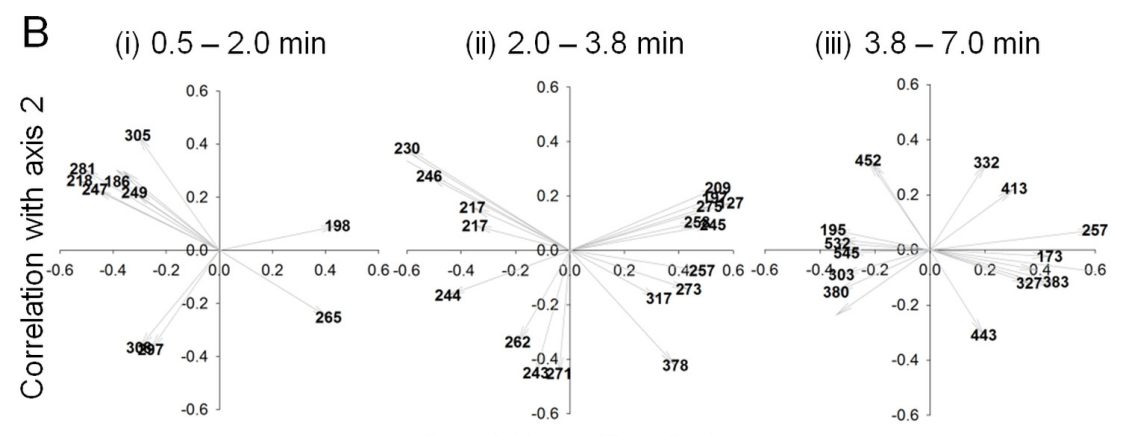

Correlation with axis 1

Figure 5. Multivariate data analysis of the exo-metabolome of Ulva mutabilis within the tripartite community (TC) and grown under axenic conditions (AC) as detected by UHPLC-ESI-ToF-MS. (A) The first two canonical axes of the CAP analysis are plotted. CAP analysis demonstrates the separation based on the states of gametogenesis along with the growth phases of Ulva mutabilis: Non-inducible gametogenesis (N.I.G., orange), artificially inducible status (A.I.G., turquoise) and spontaneously inducible status (S.I.G., light gray); (B) Scaled vectors of the metabolites $(\mathrm{m} / \mathrm{z}$ ) are presented significant for the separation. For better visualization, vectors of the metabolites were plotted according their retention times: (i) metabolites eluted between 0.50 and $2.00 \mathrm{~min}$; (ii) 2.00 and $3.80 \mathrm{~min}$; and (iii) 3.80 and $7.00 \mathrm{~min}$. Here, the numbers correspond to the $m / z\left[\mathrm{M}+\mathrm{H}^{+}\right]$values of the compounds, which can be also found in the heat map (Figure 6).

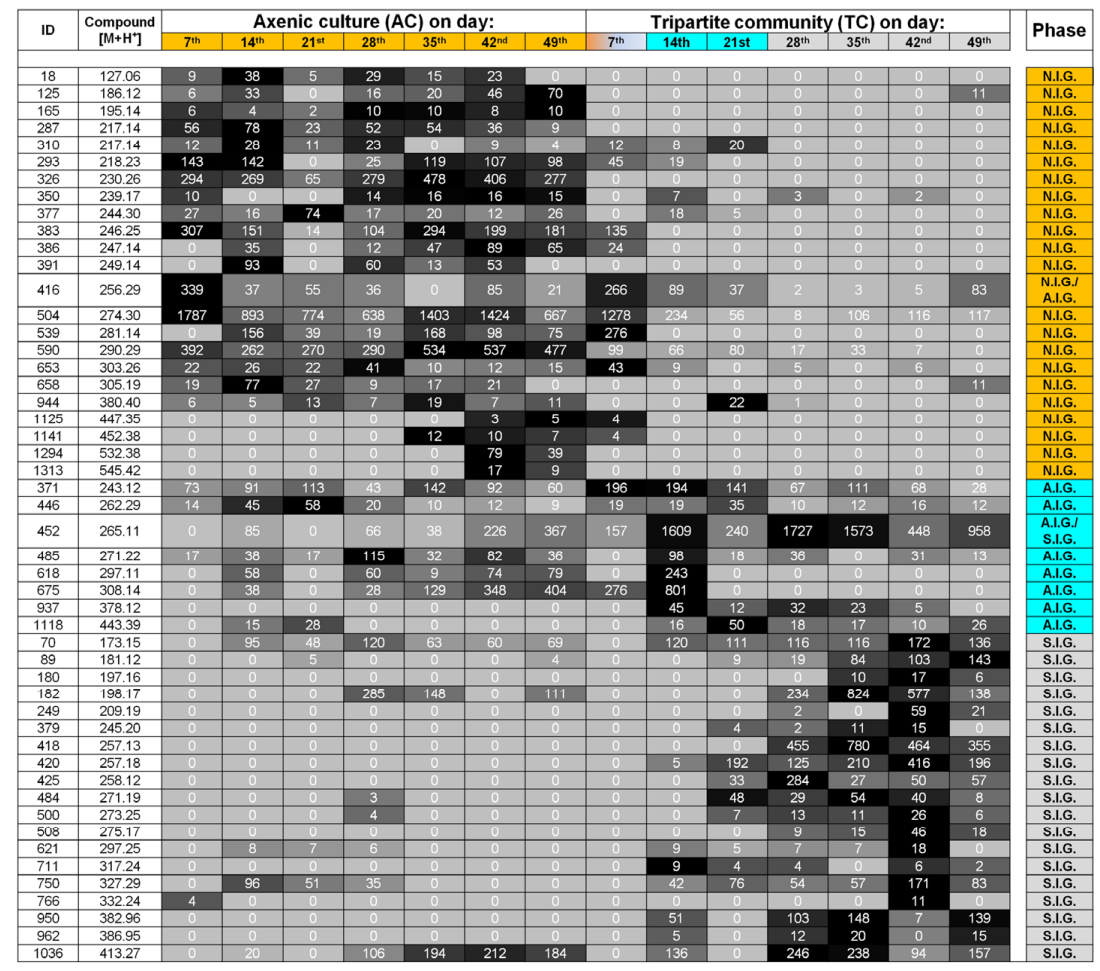

Figure 6. Heat map of the intensities of exo-metabolites, which were correlated with the CAP axis $(|\mathrm{r}|>0.3)$ and contributed to the classification of the growth phases (N.I.G., A.I.G., and S.I.G), based on UHPLC-ESI-ToF-MS analysis. Metabolites were extracted from Ulva growth medium of the tripartite community (TC) or axenic culture (AC). Relative intensities were given in the range from 0 to 2000 . Smaller values were represented by light gray and higher values by dark grey/black boxes. The color code refers to the three states of the gametogenesis: non-inducible gametogenesis (N.I.G., orange), artificial inducible status (A.I.G., turquoise) and spontaneously inducible status (S.I.G., light gray). 
2.4. Biological Interpretation and Hypothesis Generation: Metabolites Shaping the Mutualistic Interaction of Ulva and Associated Bacteria

The interactions within the tripartite community depend on both the exchange of nutrients and infochemicals, which are a fundamental feature mediating the bacterial-algal interactions within the chemosphere [8]. Hereby, the experimental design of the study did not allow, in all cases, to determine whether an identified metabolite was produced by the alga or the bacteria. The following four sections discuss potential posteriori hypotheses concerning the physiological processes underlying the inter-kingdom interactions, based on chemometric and biological data analyses.

\subsubsection{Ulva Provides Glycerol as a Potential Carbon Source for Bacterial Growth}

Glycerol was found to be released by Ulva under axenic conditions and within the tripartite community (Figures 4 and 7A,B). Therefore, growth of Roseovarius sp. MS2 in UCM supplemented with glycerol as a carbon source was assessed. Indeed, Roseovarius sp. MS2 grew well on glycerol in regard to, e.g., growth rate and final optical density (Figure 7C). Previous studies have already demonstrated that several strains of the Roseobacter clade harbor pathways for glycerol catabolism [28]. Glycerol released by Ulva likely supports growth of a wide range of bacteria resulting in biofilm formation around its holdfast.

Among these bacteria, morphogenesis-inducing bacteria would promote growth of Ulva, which in turn could then provide increased amounts of the carbon source and foster the bacterial-algal interactions. Additionally, several sugars, of which the identity could not be determined, were found in axenic cultures. They may work as a carbon source for Maribacter sp MS6, because glycerol was not utilized for growth by this strain.

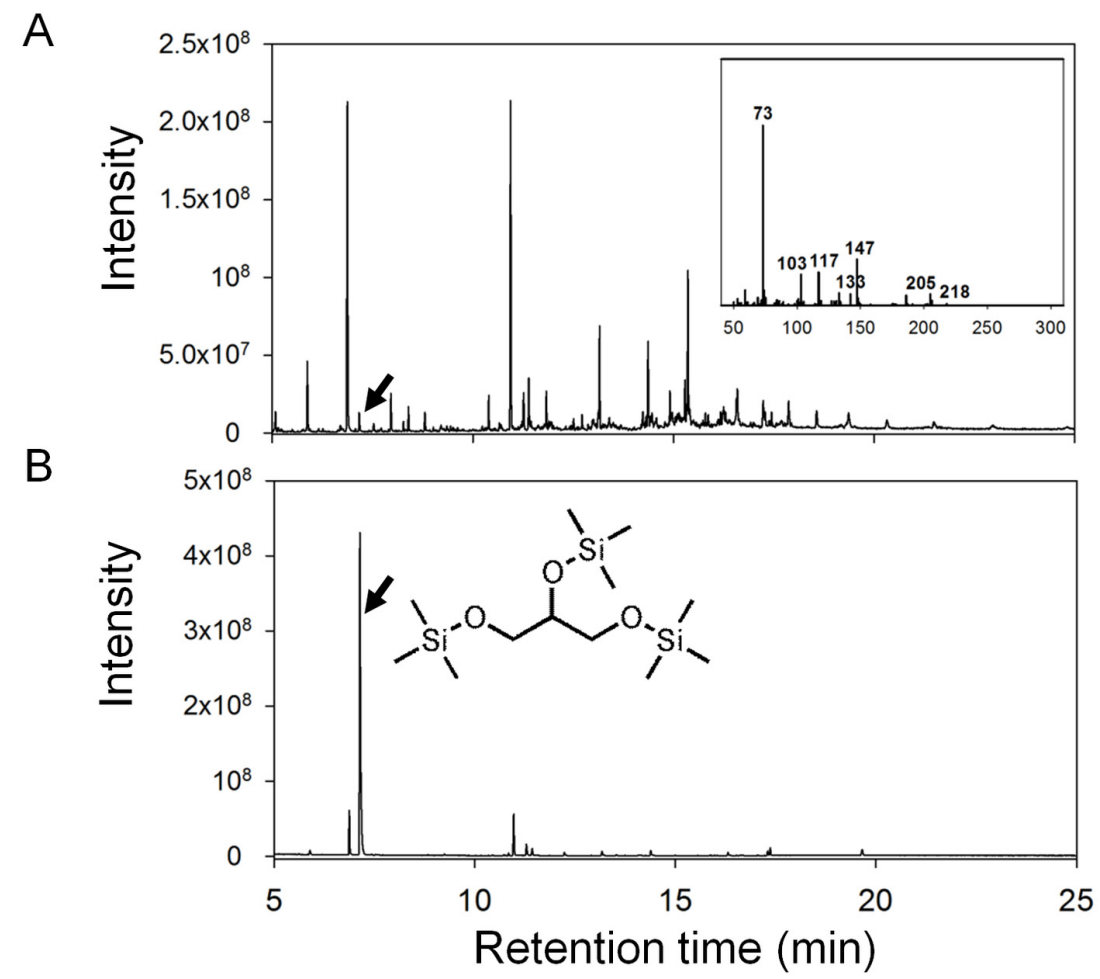

Figure 7. Cont. 


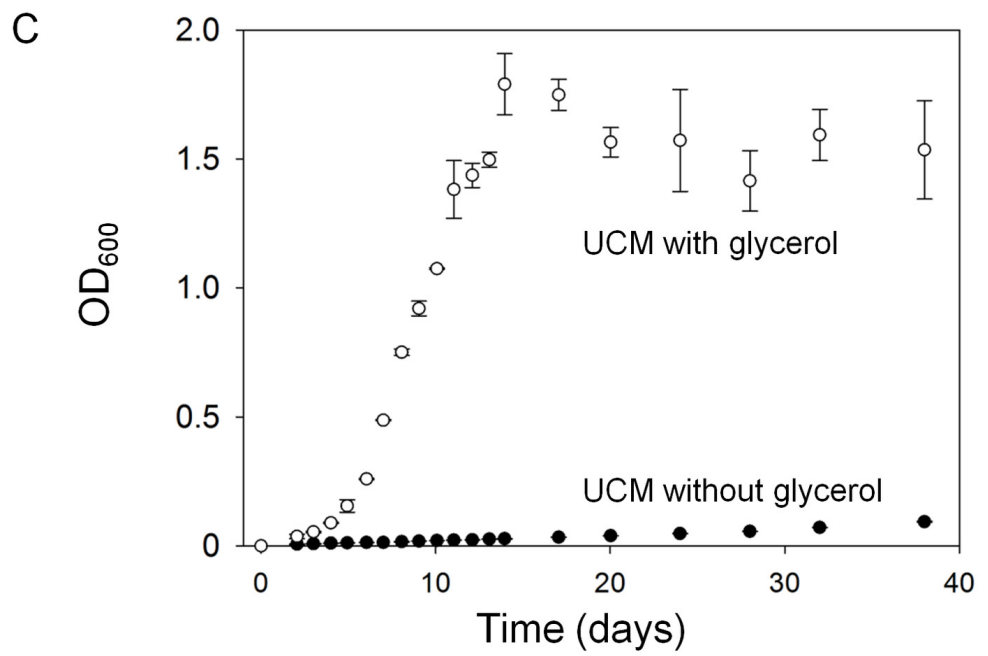

Figure 7. Utilization of glycerol as carbon source for Roseovarius sp. MS2. (A) Determination of glycerol in Ulva culture medium (UCM) of Ulva mutabilis under axenic conditions on Day 14 by comparison (B) with a reference standard upon derivatization with $N$-methyl- $N$-(trimethylsilyl)trifluoroacetamide. Total ion current chromatograms from a GC-MS analysis are presented $(\mathbf{A}, \mathbf{B})$. The mass spectrum (inset (A)) and the structure of the identified tris(trimethylsilyl) ether of glycerol (B) are shown. The molecular ion $M^{+\bullet}$ is not visible. (C) Glycerol was tested as the sole carbon source for Roseovarius sp. MS2 in UCM without Ulva. Growth curves of Roseovarius sp. MS2 in UCM with (white circle) and without (black circle) supplement of $1 \%$ glycerol (v:v) are plotted (mean values $\pm \operatorname{SD}(n=3)$ ).

\subsubsection{Organic Acids Might Increase the Bioavailability of Essential Trace Metals}

Iron occurs primarily in hardly-soluble mineral forms in aerobic environments at alkaline pHs. However, iron can be mobilized from either a mineral or organic nutrient source by organic acids (acting as chelating agents). Higher concentrations of divalent low-molecular weight organic acids, such as maleic and succinic acids, were detected in the late growth phase and may play a role in increasing the bioavailablity of unchelated ferric iron once it becomes limited (Figure 4). It has already been demonstrated in higher plants that such mechanisms can compensate for iron deficiencies [29,30]. Certainly, further targeted screenings for organic ligands are necessary to understand the eco-physiological functions of the potential metal chelators for Ulva and its associated bacteria [31]. Moreover, organic acids may also buffer the medium against increasing alkalinity, or they may themselves act as nutrients [32]. With the increase in the $\mathrm{pH}$ of the growth medium, organic acids released by bacteria and/or the alga can act as an effective buffering system, enhancing the growth of Ulva by stabilizing the $\mathrm{pH}$.

\subsubsection{Amino Acid-Mediated Signaling between Ulva and Bacteria}

A couple of unidentified amino acids were determined in the states N.I.G. and S.I.G in addition to glutamine, $S$-methyl-cysteine and O-acetyl-serine (OAS) (Figure 4). The importance of amino acids for algal-bacteria interactions has already been recognized in biofilms and in plankton, exemplified by diatoms [33]. Whereas microphytobenthic assemblages take up dissolved free amino acids efficiently [34], at the same time, rapidly growing diatoms release extracellular amino acids [35]. Although the reasons for these observations could not always be deciphered, recent studies suggest, for example, the importance of the metabolic cycle of tryptophan between diatoms (Pseudo-nitzschia multiseries) and bacteria (Sulfitobacter sp.) for promoting diatom cell division via the secretion of the hormone indole-3-acetic acid (IAA) [36]. However, there is no evidence that this mode of action is also true for the interactions between $U$. mutabilis-Roseovarius sp. MS2 or Sulfitobacter sp. 
MS1, respectively [9]. IAA did not have an effect on Ulva's growth nor on morphogenesis in experiments performed with young propagules $[9,10]$.

\subsubsection{Halogenated Phenolic Substances Might Act as Deterrents in Ulva's Chemosphere}

The halogenated phenolic compound 2,4,6-tribromophenol (TBP) was identified in the chemosphere of the tripartite community (Figure 4). TBP is known as an antibacterial and deterrent substance against marine herbivores [37-39]. It inhibits the settlement of the Japanese abalone Haliotis discus on a brown alga [40]. Bromophenols are very common volatile compounds among red [37,41] and brown algae [42,43]. Flodin et al. [44] have already proven the existence of TBP in the green alga U. lactuca [44,45]. Further studies will decipher the TBP-biosynthetic pathway in $U$. mutabilis and clarify whether TBP prevents herbivory or interferes with the growth of (symbiotic) bacteria. TBP might also be released by Ulva in order to deter other bacteria that do not provide, for example, morphogenetic factors for Ulva.

\subsection{The "Known Unknowns"}

Exo-metabolomic analyses suggested the presence of several known bioactive compounds. These biomarkers, in turn, can be used as a proxy for the status of the inducibility of gametogenesis and to, generally, identify the growth phase of $U$. mutabilis when grown in the presence of the morphogenetic/bacterial factors. However, many growth-phase-dependent biomarkers, based on GC-MS and LC-MS measurements, were classified as "unknowns" due to the tremendous chemical diversity of metabolites released into the growth media and the limitations associated with the analytical platform $[25,46]$. Identification of each uncharacterized metabolite will be, in many ways, its own puzzle, and MS- or even bioassay-guided fractionation becomes necessary to elucidate the nature of a compound. Bacterial morphogenetic compounds might not be among them, as the biologically active concentration $[9,11]$ seems to be far below the detection limit of the metabolomic approach applied. In fact, this is different to indol-3-acetic acid, which was recently determined to be responsible for the signaling between phytoplankton and bacteria [36]. However, the production and release of some "unknown" compounds suggest that they may be a key tool in understanding the interactions between Ulva and associated bacteria.

\section{Materials and Methods}

\subsection{Cultivation of $U$. mutabilis and Bacteria in Bioreactors}

Haploid gametophytes from the fast-growing developmental mutant "slender" (sl) of $U$. mutabilis Føyn (mating type mt+) [12] were cultured in this study (Figure 1A). A seed stock of axenic gametes was prepared for the cultivation of Ulva in bioreactors (Figure 1). In order to prepare the seed stock, the gametogenesis of mature gametophytes of the developmental mutant "slender" (three to four weeks old) was induced by fragmentation using a herb chopper. Fragments were washed three times with distilled water in order to remove the sporulation inhibitors (SI-1 and SI-2) [24] and were subsequently suspended in Ulva culture medium (UCM) and exposed to standard growth conditions in standard Petri dishes $(40 \mathrm{~mL})$ [24]. The gametes were discharged upon removal of the swarming inhibitor (SWI) by changing the UCM on the morning of the third day after induction. Gametes were separated from the accompanying bacteria according to a well established procedure [8] and were finally used for inoculation of an axenic (bacteria free) culture of Ulva in UCM. Axenicity was first tested by plating gamete samples on agar plates (marine broth $+2 \%$ agar, Roth) and were subsequently further confirmed by polymerase chain reaction (PCR) of the $16 \mathrm{~S}$ rRNA gene [9]. Axenic gametes $\left(\sim 6 \times 10^{3}\right.$ gametes) were incubated overnight in $250 \mathrm{~mL}$ sterile UCM in polycarbonate tissue culture flasks (BD Falcon, Franklin Lake, NJ, USA) in the dark, allowing settlement of the germ cells [5]. Those axenic germlings (feedstock) were used for the inoculation of the bioreactors (Figure 1B). Cultures were illuminated under standard conditions in a $17: 7 \mathrm{~h}$ light/dark regime at $20^{\circ} \mathrm{C}$ with $60-120 \mu \mathrm{mol}$ photons $/\left(\mathrm{m}^{2} \cdot \mathrm{s}^{2}\right)$ 
(50\% GroLux, 50\% daylight fluorescent tubes; OSRAM, München, Germany). Conditions were kept constant during the entire experiment.

The bacterial strains, Roseovarius sp. strain MS2 (Genbank EU359909) and Maribacter sp. strain MS6 (Genbank EU359911), essential for Ulva's growth and morphogenesis were cultivated at $20^{\circ} \mathrm{C}$ in marine broth medium on an orbital shaker. These bacteria were originally isolated from U. mutabilis [9]. The bacterial pellets were washed three times by re-suspending them with sterile UCM before axenic germlings were inoculated with the two bacteria in order to establish the tripartite community.

For glycerol dependent growth experiments with Roseovarius sp. MS2 without the algae, UCM was spiked with $1 \%$ glycerol (v:v), inoculated with the bacterium $(\mathrm{OD}=0.001$, which corresponds to the calculated OD in the UCM after inoculation) and cultivated at $28^{\circ} \mathrm{C}$.

Cultures of axenic algae and tripartite community in bioreactors (Figure 1B) were prepared under strictly sterile conditions with one-week-old axenic germlings. The final density was $5 \times 10^{3}$ germlings $/ 25 \mathrm{~L}$. In order to set up the tripartite community, bioreactors were first inoculated with the bacteria $\left(\mathrm{OD}_{620 \mathrm{~nm}}=0.0001\right.$, which corresponds to the calculated $\mathrm{OD}$ in the TC-bioreactors after inoculation), and, subsequently, with the axenic germlings from the feedstock. Triplicates of each axenic $(3 \times 25 \mathrm{~L})$ and the tripartite community $(3 \times 25 \mathrm{~L})$ were conducted (Figure $1 \mathrm{C})$. Duplicates of the control $(2 \times 10 \mathrm{~L})$ were performed containing only UCM in parallel. Cultures were kept in $25 \mathrm{~L}$ bioreactor culture in polycarbonate bottles (Figure 1B), adapted from Reference [47].

\subsection{Sample Collection and Storage}

One liter of the supernatant was collected weekly from each bioreactor culture and filtered through a GF/C filter (glass microfiber, $1.2 \mu \mathrm{m}$ pores, Whatman, VWR, Darmstadt, Germany) under vacuum ( $\sim 500 \mathrm{mBar}$ ). After filtration, $1 \mathrm{~L}$ filtrate was extracted using EASY ${ }^{\circledR}$ cartridges (SPE, Chromabond $3 \mathrm{~mL}$, polar-modified polystyrene-divinylbenzene copolymer, $200 \mathrm{mg}$, Macherey-Nagel, Düren, Germany). Upon conditioning of the cartridge with $5 \mathrm{~mL}$ methanol, and subsequently with $5 \mathrm{~mL}$ distilled water, the filtrate was passed through the EASY ${ }^{\circledR}$ cartridges, via Teflon tubing (flow rate $=1 \mathrm{~L} / \mathrm{h}$ ). After washing with $5 \mathrm{~mL}$ distilled water, the cartridges were air-dried and eluted by gravity with $4 \mathrm{~mL}$ of methanol:tetrahydrofuran $(1: 1, v: v)$ in glass vials. The vials were closed with caps fitted with PTFE-butyl-PTFE septa (VWR, Germany). An amount of $1 \mathrm{~mL}$ of the extract was committed to UHPLC/ESI-MS analysis and $3 \mathrm{~mL}$ was used for gas chromatography-mass spectrometry (GC-MS) analysis after derivatization, according to the protocol described by Vidoudez and Pohnert [47].

\subsection{Determination of Nutrients, Biota Data and Growth}

\subsubsection{Nitrate and Phosphate}

The initial concentrations of nitrate and phosphate in the UCM were $1 \mathrm{mmol} / \mathrm{L}$ and $0.05 \mathrm{mmol} / \mathrm{L}$, respectively, regardless of treatment. The nitrate concentration was measured by ultraviolet-visible spectroscopy (Specord M82 photospectrometer, Carl-Zeiss, Jena, Germany), based on the method of nitration of resorcinol in acidified UCM [48]. Absorption of triplicates was measured at $505 \mathrm{~nm}$ and concentrations determined with the molar extinction coefficient of $1.7 \times 10^{4} \mathrm{~L} /(\mathrm{mol} \cdot \mathrm{cm})$. Phosphate was measured upon reaction with a combined reagent containing ammonium molybdate, ascorbic acid, and potassium antimonyl titrate. The resulting complex was reduced in situ to a blue colored solution. Absorption of triplicates was measured at $885 \mathrm{~nm}$ [49]. The concentrations of nitrate and phosphate in the UCM were determined $\left(C_{i}\right)$ before inoculation, and then according to the weekly sampling scheme (Figure 2).

The utilization rate of nitrate and phosphate was calculated according to the following equation

$$
\text { Utilization Rate }(100 \%)=\frac{C_{i}-C_{a}}{C_{i}} \times 100
$$


where $C_{a}$ is the concentration of the nutrient following a given week, and $C_{i}$ is the initial concentration of the nutrient in the growth medium [50].

\subsubsection{Life Cycle Regulating Factors}

The activity of the swarming inhibitor (SWI) was determined in the growth medium $(n=3)$, weekly, according to published protocols [18,24]. One unit of SWI is defined as the minimal amount of the factor, a compound of low molecular weight (292 Da), inhibiting gamete release in $1 \mathrm{~mL}$ UCM under standard conditions $[18,24]$. The amounts of units $/ \mathrm{mL}$ in the growth medium are determined through a dilution series.

\subsubsection{Monitoring of Ulva's Growth}

The length of $U$. mutabilis in the tripartite communities was measured with a ruler, once, the week after inoculation, on Day 7. The average length of three thalli from each population was calculated and plotted as a function of time. The drained-weight of thalli were measured and the relative growth rate (RGR) was calculated according to References [51,52].

$$
G R\left(\% \text { day }^{-1}\right)=100 \times \ln \left(W_{2} / W_{1}\right) /\left(t_{2}-t_{1}\right)
$$

where $W_{1}$ is the drained weight (in g) at time point $1, W_{2}$ is the drained weight (in g) at time point 2, and $t_{1}$ and $t_{2}$ are equal to the time in days. RGR is given in $\%$ per day.

The growth in the axenic cultures was estimated by measuring the diameter of the callus-like colonies.

\subsubsection{DNA Extraction and PCR Amplification for Monitoring Axenicity and Bacterial Growth}

PCR was performed to prove the absence or presence of bacteria in the UCM and to provide amplicons for DGGE. Samples for analysis of the tripartite community and for axenicity tests were taken weekly under sterile conditions. An amount of $50 \mathrm{~mL}$ of culture medium was filtered using a polycarbonate filter (Millipore ISOPORE ${ }^{(T M)}, 0.2 \mu \mathrm{m}$ GTTP $25 \mathrm{~mm}$, Sigma Aldrich, München, Germany) in a polysulfone filter holder for syringes, and stored at $-80^{\circ} \mathrm{C}$ until extraction using a QIAamp DNA Mini Kit (Qiagen, Hilden, Germany). DNA was extracted based on the protocol of the QIAmp Blood DNA extraction kit (Qiagen Manual, 2nd Edition) metagenomics. All experiments were performed under strictly sterile conditions.

The nucleotide sequence for the forward primer, which is specific for eubacteria, contains a GC clamp (357fGC; CGC CCG CCG CGC GCG GCG GGC GGG GCG GGG GCA CGG GGG GCC TAC GGG AGG CAG CAG). The universal consensus sequence was used as reverse primer (907rM; CCG TCA ATT CMT TTG AGT TT) [53]. The PCRs, as well as the DGGE, were performed by using AmpliTag Gold DNA Polymerase (Applied Biosystems, Foster City, CA, USA) according to Grueneberg et al. [11].

\subsection{Sample Preparation and GC-MS Analysis}

\subsubsection{Derivatization}

Five $\mu \mathrm{L}$ of a ribitol (Sigma-Aldrich, München, Germany) stock solution ( $4 \mathrm{mmol} / \mathrm{L}$ in water) was added to a volume of $1.5 \mathrm{~mL}$ of each extracted sample (Section 3.2) as internal standard. After evaporation of the solvent, $50 \mu \mathrm{L}$ of a methoxyamine hydrochloride (Sigma-Aldrich) solution $(20 \mathrm{mg} / \mathrm{mL})$ in pyridine was added for derivatization and incubated at $60{ }^{\circ} \mathrm{C}$ for $1 \mathrm{~h}$, or at $20^{\circ} \mathrm{C}$ for an additional $9 \mathrm{~h}$ [47]. Subsequently, $50 \mu \mathrm{L}$ of $N$-Methyl- $N$-(trimethylsilyl)trifluoroacetamide (Macherey-Nagel, Düren, Germany), supplemented with decane, pentadecane, nonadecane, octacosane, dotriacontane (each final concentration $=40 \mu \mathrm{mol} / \mathrm{L}$ ) and hexatriacontane (final concentration $=20 \mu \mathrm{mol} / \mathrm{L}$ ) (Sigma-Aldrich) was added to each sample for the calculation of the 
retention time index, and incubated at $40{ }^{\circ} \mathrm{C}$ for $1 \mathrm{~h}$. The samples were transferred into $100 \mu \mathrm{L}$ glass inserts of $1.5 \mathrm{~mL}$ vials and measured directly using GC-MS [47].

\subsubsection{GC-ToF-MS Parameters}

A Waters GCT premier (Waters, Manchester, UK) orthogonal reflectron time-of-flight mass spectrometer (TOF-MS) coupled to an Agilent 6890N gas chromatograph (GC, Agilent, Santa Clara, CA, USA), equipped with a DB- $5 \mathrm{~ms}$ column ( $38 \mathrm{~m}$ long, $0.25 \mathrm{~mm}$ internal diameter, $0.25 \mu \mathrm{m}$ film thicknesses, with $10 \mathrm{~m}$ Duraguard pre-column), was used for GC-EI-MS measurements. The samples were injected with a 7683B autosampler equipped with a $10-\mu \mathrm{L}$ tapered, fixed needle, polytetrafluorethylene (PTFE)-tipped plunger syringe. Samples were run in a randomized order. After 20 measurements, a new deactivated glass liner $(4 \times 6.3 \times 78.5 \mathrm{~mm}$ inner $\varnothing \times$ outer $\varnothing \times$ length $)$ was used. The column and all spare parts were purchased from Agilent (Waldbronn, Germany). The GC parameters for the analysis were as follows: The carrier gas was helium at constant flow of $1 \mathrm{~mL} / \mathrm{min}$. The injection pre-dwell time was set at $0.1 \mathrm{~min}$ (hot needle injection). The injector temperature was $300{ }^{\circ} \mathrm{C}$. An amount of $1 \mu \mathrm{L}$ was injected into the split mode at a ratio of 1:5. The temperature program of the oven was set at $60{ }^{\circ} \mathrm{C}$ for $1 \mathrm{~min}$ at the beginning; then, the temperature was ramped up to the final temperature of $310{ }^{\circ} \mathrm{C}$ at $15{ }^{\circ} \mathrm{C} / \mathrm{min}$ (held for $9.3 \mathrm{~min}$ ) [5]. Calibration of the beam steering, the focusing lenses, and the dynamic range extension (DRE) was performed before every experiment. MS parameters were set as follows: Electron energy $=70 \mathrm{eV}$, trap current $=200 \mu \mathrm{A}$, source temperature $=300{ }^{\circ} \mathrm{C}$, transfer line temperature $=280{ }^{\circ} \mathrm{C}$, scan rate $=5 \mathrm{scans} / \mathrm{s}$, mass range was set from 50 to $800 \mathrm{~m} / \mathrm{z}$, and the DRE was activated.

\subsection{Sample Preparation and LC-MS Analysis}

A Waters Acquity Ultra Performance LC (UHPLC, Waters, Eschborn, Germany) equipped with a $30 \mathrm{~mm}$ Fortis UHPLC C18 column (2.1 mm, $1.7 \mu \mathrm{m}$, Dichrom, Marl, Germany) was used for separation at $21{ }^{\circ} \mathrm{C}$. Each sample $(10 \mu \mathrm{L})$ was injected three times for technical replicates. The mobile phases were water spiked with $0.1 \%$ formic acid and $2 \%$ acetonitrile (A) and acetonitrile spiked with $0.1 \%$ formic acid (B) (v:v). The linear LC gradient was ramped up within $7 \mathrm{~min}$ from $0 \%$ to $100 \% \mathrm{~B}$, held for $2 \mathrm{~min}$ at $100 \% \mathrm{~B}$, then $9.5 \mathrm{~min}$ at $0 \% \mathrm{~B}$ and held for $0.5 \mathrm{~min}$ at $0 \% \mathrm{~B}$. The flow rate was $0.6 \mathrm{~mL} / \mathrm{min}$ [5]. The UHPLC was coupled to a quadrupole (Q)-TOF Micromass spectrometer (Manchester, UK) using an electrospray ionization source in positive ion mode with a scan rate of $1 \mathrm{scan} / \mathrm{s}$, an inter-scan delay of $0.1 \mathrm{~s}$ and a scan range from 100 to $1000 \mathrm{~m} / z$ [54,55].

\subsection{Data Processing}

\subsubsection{GC-MS}

All chromatograms were corrected with the Component Detection Algorithm implemented in Masslynx ${ }^{\mathrm{TM}}$ (version 4.1, Waters, Manchester, UK) for background signals. The MCQ index was set at 0.8 and the smoothing window was 3 points. The chromatograms were transferred to network common data files by the Masslynx ${ }^{\mathrm{TM}}$ DataBridge (Micromass, V4.1). Co-inverted spectra were treated in batch jobs in the Automated Mass spectral Deconvolution and Identification System (AMDIS; version 2.65, National Institute of Standards and Technology (NIST, Gaithersburg, MD, USA)). The following parameters were used: minimum match factor $=30$, type of analysis $=$ simple, component width $=32$, omitted $m / z$ values: 147, 176, 193, 207 and 219, adjacent peak subtraction $=2$, resolution $=$ low, sensitivity $=$ medium, and shape requirement $=$ low. The common data files and the corresponding AMDIS files were fed into METabolomics-Ion-based Data Extraction Algorithm (MET-IDEA) (version 2.03). Following parameters were applied: average peak width $=0.08$, AMDIS transfer $=0.5$, maximum peak width $=2$, peak start $/$ stop slope $=1.5$, adjusted retention time accuracy $=0.25$, peak overload factor $=0.9$, MS type $=$ TOF, mass accuracy $=0.1$, mass range $=0.3$, excluded ions $=73,147,193,281,341$ and 415 , lower mass limit $=100$, and ions per component $=1$ [5]. 
Signals corresponding to the retention index standards and ribitol were deleted prior to the chemometric analyses.

\subsubsection{LC-MS}

MarkerLynx ${ }^{\mathrm{TM}}$ (Version 4.1, Waters, UK) was used for the acquisition of the mass-retention time pairs. This application integrates peaks using ApexTrac ${ }^{\mathrm{TM}}$ peak detection and implements basic peak detection and baseline determination algorithms. The processing parameters that control peak detection and baseline placement are independent of each other and were set at a peak width of $5 \%$, peak width of $5 \%$ height $(s)=15$, peak-to-peak baseline ratio $=0$, noise elimination $=0.10$, intensity threshold $=10, \mathrm{~m} / \mathrm{z}$ window $=0.05 \mathrm{amu}$, and at a retention time window $=1 \mathrm{~min}$.

\subsection{Statistical Analysis}

Post hoc comparisons for all metadata were performed using Tukey's HSD (honestly significant difference) test at a probability level of $\alpha=0.05$ to determine pairwise differences between treatments (Minitab 16.2.4, Friedrichsdorf, Germany).

Canonical analysis of principle coordinates (CAP) was used for multivariate data analysis to visualize differences in exo-metabolite assemblages during algal growth. The procedure couples principal coordinate analysis ( $\mathrm{PCo} A)$, an ordination procedure and a generalization of a principal component analysis, with a canonical analysis. The unconstrained ordinates share the common feature that the experimental units are not divided into groups and they do not provide any null hypothesis that can be tested statistically. Therefore, in addition to PCoA, the CAP computer program (version 12) performs two further distinct statistical procedures: The first step is the canonical discriminant analysis, in which the experimental units are arranged in predefined groups (a priori hypotheses) and the null hypothesis is that the multidimensional vectors of means do not differ [56]. Then, the permutation test provided an exact, nonparametric $p$-value for that null hypothesis [57]. Within this routine, the principal coordinates (PCo) were calculated from the Bray-Curtis resemblance matrix, and potential over-parameterization was prevented by choosing the number of PCo axes $(m)$ that maximized a leave-one-out allocation success to the groups [27,58,59]. Data were transformed to square root and standardized by row (i.e., samples) sums.

The canonical test statistics were significant for both GC-MS and LC-MS data sets. Using a total of 999 permutations, the $p$-value was 0.001 , obtained from the permutation test using CAP [27,58]. As 0.001 is equal to $1 /(999+1)$, it has been demonstrated that no randomly permuted data set had a more drastically different biomarker assemblage than that of the data set examined.

The resulting first two canonical axes and sample coordinates were then imported into SigmaPlot (version 11.0, Systat Software, Erkrath, Germany) for graphical illustration. Chemical biomarkers responsible for differences among the treatments and growth phases were identified by the strength of their correlation of the canonical discriminant axes coordinates with the indicative compounds. Depiction of the vectors of these metabolites on the CAP axis allowed determination, in which grouping was important. The Pearson correlation coefficients were scaled to the CAP range of the coordinates (usually between $|\mathrm{r}|>0.3-0.5$ ) to generate the vectors corresponding to each significant compound (Figures 3B and 5B). Hereby, the two-tailed probability value, $p$, is equal to 0.05 (maximum $p$ value applied in this study) when a Pearson correlation value of $|\mathrm{r}|=0.3$ and a sample size of $n=43$ were given (exemplified for the data set of the GC-MS analysis). Therefore, only biomarker correlations of $|\mathrm{r}|>0.3$ were considered as significant.

\subsection{Annotation of Metabolites Acquired by GC-MS Analysis}

The spectrum of each peak retained for analysis was manually examined and identification was attempted using the software MS search (version $2.0 \mathrm{~d}$, NIST). The following libraries were used: NIST, Golm Metabolome Database (Version: 121_VAR5_ALK_MSP) and MPI of Molecular Plant Physiology (Version: Q_MSRI_ID2004-03-01). A structure was accepted if the reverse match was higher than 800 
and if the retention index was close to the index provided in the libraries [5]. Structures with a reverse match between 800 and 700 were tagged with a "?" and structures with a reverse match below 700 with "??". Reverse match factors below 600 were not accepted. Finally, proposed compounds were compared with reference standards in certain cases, as illustrated for glycerol (Figure 7).

\section{Conclusions}

We analyzed the exo-metabolome during macroalgal growth in the presence of a designed and simplified microbiome. The possibility of controlling growth conditions precisely and obtaining large amounts of homogeneous sample material was a necessity to study complex exo-metabolic changes with a high temporal resolution, as has already been shown for microalgae, such as Chlamydomonas [60].

This study has demonstrated that the release and persistence of extracellular organic compounds depends on the interaction of Ulva with the tested bacteria, and on the growth stage. Differences in biomarker assemblages revealed changes in Ulva growth phases. Overall, metabolomics is a key tool for bridging the gap between the environment and Ulva's holobiont, interacting directly via the exchange of, for example, infochemicals, and indirectly through the recruitment of, for example, nutrients. However, the majority of compounds were classified as "known unknowns".

The GC-MS-based metabolomic data set of identified compounds, along with the metadata, leads to new hypotheses regarding the chemical ecology of $U$. mutabilis. We believe it is worthwhile pursuing more work on the structure elucidation of the phase-dependent compounds identified, because they can be used as robust proxies of the physiological status of a tripartite community. Bacteria, grown on ${ }^{13} \mathrm{C}$-labeled carbon sources, which are utilized for the synthesis of bacterial metabolites, will help to differentiate between algal and bacterial compounds in the chemosphere. In addition, the combined approach of transcriptomics and metabolomics may reveal novel insights into how the physiology of Ulva is changing in its time course-dependent chemosphere.

Supplementary Materials: The following is available online at www.mdpi.com/1660-3397/15/1/14/s1: Figure S1: Multivariate data analysis (PCoA) of the exo-metabolome of Ulva mutabilis within the tripartite community (TC) and grown under axenic conditions (AC) after GC-MS and LC-MS analyses.

Acknowledgments: We thank Taif University (Kingdom of Saudi Arabia) for the Ph.D. fellowship to T.A. This work was supported partly by the Deutsche Forschungsgemeinschaft (DFG) through the CRC 1127 ChemBioSys and the Jena School for Microbial Communication (JSMC) to A.W. and T.W. We thank Georg Pohnert for his great support throughout this study and Hannes Richter (Friedrich Schiller University Jena) for the nutrient analysis. We sincerely thank three reviewers for valuable comments, which were of great help in revising the manuscript.

Author Contributions: All experiments were conducted by T.A. except the bacteria cultivation experiments, which were performed by A.W. Design of the experiments and data analysis and interpretations were conducted by T.A. and T.W. T.A. and T.W. wrote the manuscript, which was approved by all authors.

Conflicts of Interest: The authors declare no conflicts of interest.

\section{Abbreviations}

The following abbreviations are used in this manuscript:

AC axenic culture

A.I.G. artificially inducible gametogenesis

CAP canonical analysis of principle coordinates

DGGE denaturing gradient gel electrophoresis

DRE dynamic range extension

EI electron impact

ESI electrospray ionization

GC gas chromatography

IAA indole-3-acetic acid

LC liquid chromatography

MS mass spectrometry

N.I.G. non-inducible gametogenesis

OD optical density

PCoA principal coordinate analysis 


$\begin{array}{ll}\text { PCR } & \text { poly chain reaction } \\ \text { SI } & \text { sporulation inhibitor } \\ \text { S.I.G. } & \text { spontaneously inducible gametogenesis } \\ \text { SFA } & \text { Saturated fatty acids } \\ \text { SWI } & \text { swarming inhibitor } \\ \text { TBP } & \text { 2,4,6-tribromophenol } \\ \text { TC } & \text { tripartite community } \\ \text { ToF } & \text { time-of-flight mass spectrometer } \\ \text { UCM } & \text { Ulva culture medium } \\ \text { UHPLC } & \text { ultra-high pressure liquid chromatography } \\ \text { UR } & \text { utilization rate }\end{array}$

\section{References}

1. Little, A.E.F.; Robinson, C.J.; Brook Peterson, S.; Raffa, K.F.; Handelsman, J. Rules of engagement: Interspecies interactions that regulate microbial communities. Annu. Rev. Microbiol. 2008, 62, 375-401. [CrossRef] [PubMed]

2. Azam, F.; Malfatti, F. Microbial structuring of marine ecosystems. Nat. Rev. Microbiol. 2007, 5, $782-791$. [CrossRef] [PubMed]

3. Jewett, M.C.; Hofmann, G.; Nielsen, J. Fungal metabolite analysis in genomics and phenomics. Curr. Opin. Biotechnol. 2006, 17, 191-197. [CrossRef] [PubMed]

4. Roessner, U.; Bowne, J. What is metabolomics all about? BioTechniques 2009, 46, 363-365. [CrossRef] [PubMed]

5. Alsufyani, T. Metabolite Profiling of the Chemosphere of the Macroalga Ulva (Ulvales, Chlorophyta) and Its Associated Bacteria Dissertation; Friedrich Schiller University Jena: Jena, Germany, 2014.

6. Goecke, F.; Labes, A.; Wiese, J.; Imhoff, J.F. Chemical interactions between marine macroalgae and bacteria. Mar. Ecol. Prog. Ser. 2010, 409, 267-300. [CrossRef]

7. Joint, I.; Tait, K.; Wheeler, G. Cross-kingdom signalling: Exploitation of bacterial quorum sensing molecules by the green seaweed Ulva. Philos. Trans. R. Soc. B 2007, 362, 1223-1233. [CrossRef] [PubMed]

8. Wichard, T. Exploring bacteria-induced growth and morphogenesis in the green macroalga order Ulvales (Chlorophyta). Front. Plant Sci. 2015, 6, 86. [CrossRef] [PubMed]

9. Spoerner, M.; Wichard, T.; Bachhuber, T.; Stratmann, J.; Oertel, W. Growth and thallus morphogenesis of Ulva mutabilis (Chlorophyta) depends on a combination of two bacterial species excreting regulatory factors. J. Phycol. 2012, 48, 1433-1447. [CrossRef] [PubMed]

10. Fries, L.; Aberg, S. Morphogenetic effects of phenylacetic and p-OH-phenylacetic acid on green-alga Enteromorpha compressa (L.) grev in axenic culture. Z. Pflanzenphysiol. 1978, 88, 383-388. [CrossRef]

11. Grueneberg, J.; Engelen, A.H.; Costa, R.; Wichard, T. Macroalgal morphogenesis induced by waterborne compounds and bacteria in coastal seawater. PLoS ONE 2016, 11, e0146307. [CrossRef] [PubMed]

12. Føyn, B. Über die Sexualität und den Generationswechsel von Ulva mutabilis. Arch. Protistenkd. 1958, 102, 473-480.

13. Føyn, B. Geschlechtskontrollierte Vererbung bei der marinen Grünalge Ulva mutabilis. Arch. Protistenkd. 1959, 104, 236-253.

14. Løvlie, A. Genetic control of division rate and morphogenesis in Ulva mutabilis Føyn. C. R. Trav. Lab. Carlsberg 1964, 34, 77-168.

15. Oertel, W.; Wichard, T.; Weissgerber, A. Transformation of Ulva mutabilis (Chlorophyta) by vector plasmids integrating into the genome. J. Phycol. 2015, 51, 963-979. [CrossRef] [PubMed]

16. Wichard, T.; Charrier, B.; Mineur, F.; Bothwell, J.H.; De Clerck, O.; Coates, J.C. The green seaweed Ulva: A model system to study morphogenesis. Front. Plant Sci. 2015, 6, 72. [CrossRef] [PubMed]

17. Zhang, X.; Ye, N.; Liang, C.; Mou, S.; Fan, X.; Xu, J.; Xu, D.; Zhuang, Z. De novo sequencing and analysis of the Ulva linza transcriptome to discover putative mechanisms associated with its successful colonization of coastal ecosystems. BMC Genom. 2012, 13, 565. [CrossRef] [PubMed]

18. Stratmann, J.; Paputsoglu, G.; Oertel, W. Differentiation of Ulva mutabilis (Chlorophyta) gametangia and gamete release are controlled by extracellular inhibitors. J. Phycol. 1996, 32, 1009-1021. [CrossRef]

19. Vesty, E.F.; Kessler, R.W.; Wichard, T.; Coates, J.C. Regulation of gametogenesis and zoosporogenesis in Ulva linza (Chlorophyta): Comparison with Ulva mutabilis and potential for laboratory culture. Front. Plant Sci. 2015, 6, 15. [CrossRef] [PubMed] 
20. Nilsen, G.; Nordby, O. Sporulation inhibiting substance from vegetative thalli of green alga Ulva mutabilis Føyn. Planta 1975, 125, 127-139. [PubMed]

21. Muyzer, G.; Teske, A.; Wirsen, C.O.; Jannasch, H.W. Phylogenetic-relationships of Thiomicrospira species and their identification in deep-sea hydrothermal vent samples by denaturing gradient gel-electrophoresis of $16 \mathrm{~S}$ rDNA fragments. Arch. Microbiol. 1995, 164, 165-172. [CrossRef] [PubMed]

22. Sneed, J.M.; Pohnert, G. The green alga Dicytosphaeria ocellata and its organic extracts alter natural bacterial biofilm communities. Biofouling 2011, 27, 347-356. [CrossRef]

23. Naldi, M.; Viaroli, P. Nitrate uptake and storage in the seaweed Ulva rigida C. Agardh in relation to nitrate availability and thallus nitrate content in a eutrophic coastal lagoon (Sacca di Goro, Po River Delta, Italy). J. Exp. Mar. Biol. Ecol. 2002, 269, 65-83. [CrossRef]

24. Wichard, T.; Oertel, W. Gametogenesis and gamete release of Ulva mutabilis and Ulva lactuca (Chlorophyta): Regulatory effects and chemical characterization of the "swarming inhibitor". J. Phycol. 2010, 46, 248-259. [CrossRef]

25. Bowen, B.P.; Northen, T.R. Dealing with the unknown: Metabolomics and metabolite atlases. J. Am. Soc. Mass Spectrom. 2010, 21, 1471-1476. [CrossRef] [PubMed]

26. Little, J.L.; Cleven, C.D.; Brown, S.D. Identification of "Known Unknowns" utilizing accurate mass data and chemical abstracts service databases. J. Am. Soc. Mass Spectrom. 2011, 22, 348-359. [CrossRef] [PubMed]

27. Anderson, M.J.; Robinson, J. Generalised discriminant analysis based on distances. Aust. N. Z. J. Stat. 2003, 45, 301-318. [CrossRef]

28. Miller, T.R.; Hnilicka, K.; Dziedzic, A.; Desplats, P.; Belas, R. Chemotaxis of Silicibacter sp. strain TM1040 toward dinoflagellate products. Appl. Environ. Microbiol. 2004, 70, 4692-4701. [CrossRef] [PubMed]

29. Thorpe, T.; Stasolla, C.; Yeung, E.C.; de Klerk, G.-J.; Roberts, A.; George, E.F. The Components of Plant Tissue Culture Media II: Organic Additions, Osmotic and pH Effects, and Support Systems in Plant Propagation by Tissue Culture; George, E.F., Hall, M.A., De Klerk, G.-J., Eds.; Springer: Berlin, Germany, 2008; pp. 115-174.

30. Ojima, K.; Ohira, K. The exudation and characterization of iron-solubilizing compounds in a rice cell suspension culture. Plant Cell Physiol. 1980, 21, 1151-1161.

31. Wichard, T. Identification of metallophores and organic ligands in the chemosphere of the marine macroalga Ulva (Chlorophyta) and at land-sea interfaces. Front. Mar. Sci. 2016, 3, 131. [CrossRef]

32. White, M.C.; Decker, A.M.; Chaney, R.L. Metal complexation in xylem fluid: I. chemical composition of tomato and soybean stem exudate. Plant Physiol. 1981, 67, 292-300. [CrossRef] [PubMed]

33. Bruckner, C.G.; Rehm, C.; Grossart, H.-P.; Kroth, P.G. Growth and release of extracellular organic compounds by benthic diatoms depend on interactions with bacteria. Environ. Microbiol. 2011, 13, 1052-1063. [CrossRef] [PubMed]

34. Nilsson, C.; Sundbäck, K. Amino acid uptake in natural microphytobenthic assemblages studied by microautoradiography. Hydrobiologia 1996, 332, 119-129. [CrossRef]

35. Myklestad, S.; Holm-Hansen, O.; Vårum, K.M.; Volcani, B.E. Rate of release of extracellular amino acids and carbohydrates from the marine diatom Chaetoceros affinis. J. Plankton Res. 1989, 11, 763-773. [CrossRef]

36. Amin, S.A.; Hmelo, L.R.; van Tol, H.M.; Durham, B.P.; Carlson, L.T.; Heal, K.R.; Morales, R.L.; Berthiaume, C.T.; Parker, M.S.; Djunaedi, B.; et al. Interaction and signalling between a cosmopolitan phytoplankton and associated bacteria. Nature 2015, 522, 98-101. [CrossRef] [PubMed]

37. Etahiri, S.; El Kouri, A.K.; Bultel-Ponce, V.; Guyot, M.; Assobhei, O. Antibacterial bromophenol from the marine red alga Pterosiphonia complanala. Nat. Prod. Commun. 2007, 2, 749-752.

38. Xu, N.; Fan, X.; Yan, X.; Li, X.; Niu, R.; Tseng, C.K. Antibacterial bromophenols from the marine red alga Rhodomela confervoides. Phytochemistry 2003, 62, 1221-1224. [CrossRef]

39. Liu, M.; Hansen, P.E.; Lin, X. Bromophenols in Marine algae and Their Bioactivities. Mar. Drugs 2011, 9 , 1273-1292. [CrossRef] [PubMed]

40. Li, J.-Y.; Agatsuma, Y.; Taniguchi, K. Inhibitory effect of 2,4-dibromophenol and 2,4,6-tribromophenol on settlement and survival of larvae of the Japanese Abalone Haliotis discus hannai Ino. J. Shellfish Res. 2009, 28, 877-882. [CrossRef]

41. Xu, X.L.; Song, F.H.; Fan, X.; Fang, N.Q.; Shi, J.G. A novel bromophenol from marine red alga Symphyocladia latiuscula. Chem. Nat. Compd. 2009, 45, 811-813. [CrossRef] 
42. Chung, H.Y.; Ma, W.C.J.; Ang, P.O.; Kim, J.-S.; Chen, F. Seasonal variations of bromophenols in brown algae (Padina arborescens, Sargassum siliquastrum, and Lobophora variegata) collected in Hong Kong. J. Agric. Food Chem. 2003, 51, 2619-2624. [CrossRef] [PubMed]

43. Shibata, T.; Miyasaki, T.; Miyake, H.; Tanaka, R.; Kawaguchi, S. The Influence of phlorotannins and bromophenols on the feeding behavior of marine herbivorous gastropod turbo cornutus. Am. J. Plant Sci. 2014, 5, 387-392. [CrossRef]

44. Flodin, C.; Whitfield, F.B. Biosynthesis of bromophenols in marine algae. Water Sci. Technol. 1999, 40, 53-58. [CrossRef]

45. Flodin, C.; Helidoniotis, F.; Whitfield, F.B. Seasonal variation in bromophenol content and bromoperoxidase activity in Ulva lactuca. Phytochemistry 1999, 51, 135-138. [CrossRef]

46. Quanbeck, S.M.M.; Brachova, L.; Campbell, A.A.; Guan, X.; Perera, A.; He, K.; Rhee, S.Y.; Bais, P.; Dickerson, J.; Dixon, P.; et al. Metabolomics as a hypothesis-generating functional genomics tool for the annotation of Arabidopsis thaliana genes of "unknown function". Front. Plant Sci. 2012, 3, 15. [CrossRef] [PubMed]

47. Vidoudez, C.; Pohnert, G. Comparative metabolomics of the diatom Skeletonema marinoi in different growth phases. Metabolomics 2012, 8, 654-669. [CrossRef]

48. Zhang, J.Z.; Fischer, C.J. A simplified resorcinol method for direct spectrophotometric determination of nitrate in seawater. Mar. Chem. 2006, 99, 220-226. [CrossRef]

49. Parsons, T.R.; Maita, L.; Lalli, M. A Manual of Chemical and Biological Methods of Seawater Analysis; Pergamon Press: New York, NY, USA, 1984.

50. Miyamura, S. Cytoplasmic inheritance in green algae: Patterns, mechanisms and relation to sex type. J. Plant Res. 2010, 123, 171-184. [CrossRef] [PubMed]

51. Lüning, K. Seaweeds. Their Environment, Biogeography, and Ecophysiology; Wiley-Interscience Publication: New York, NY, USA, 1990.

52. Olischlaeger, M.; Bartsch, I.; Gutow, L.; Wiencke, C. Effects of ocean acidification on growth and physiology of Ulva lactuca (Chlorophyta) in a rockpool-scenario. Phycol. Res. 2013, 61, 180-190. [CrossRef]

53. Muyzer, G.; Dewaal, E.C.; Uitterlinden, A.G. Profiling of complex microbial populations by denaturing gradient gel electrophoresis analysis of polymerase chain reaction amplified genes coding for $16 S$ ribosomal RNA. Appl. Environ. Microbiol. 1993, 59, 695-700. [PubMed]

54. Barofsky, A.; Simonelli, P.; Vidoudez, C.; Troedsson, C.; Nejstgaard, J.C.; Jakobsen, H.H.; Pohnert, G. Growth phase of the diatom Skeletonema marinoi influences the metabolic profile of the cells and the selective feeding of the copepod Calanus spp. J. Plankton Res. 2010, 32, 263-272. [CrossRef]

55. Barofsky, A.; Vidoudez, C.; Pohnert, G. Metabolic profiling reveals growth stage variability in diatom exudates. Limnol. Oceanogr. Methods 2009, 7, 382-390. [CrossRef]

56. Ratkowsky, D.A.; Gates, G.M. Generalised canonical correlations analysis for explaining macrofungal species assemblages. Australas. Mycol. 2008, 27, 33-40.

57. Ratkowsky, D.A. Visualising macrofungal species assemblage compositions using canonical discriminant analysis. Australas. Mycol. 2007, 26, 75-85.

58. Anderson, M.; Willis, T. Canonical analysis of principal coordinates: A useful method of constrained ordination for ecology. Ecology 2003, 84, 511-525. [CrossRef]

59. Hanson, C.E.; Hyndes, G.A.; Wang, S.F. Differentiation of benthic marine primary producers using stable isotopes and fatty acids: Implications to food web studies. Aquat. Bot. 2010, 93, 114-122. [CrossRef]

60. Bölling, C.; Fiehn, O. Metabolite profiling of Chlamydomonas reinhardtii under nutrient deprivation. Plant Physiol. 2005, 139, 1995-2005. [CrossRef] [PubMed]

(C) 2017 by the authors; licensee MDPI, Basel, Switzerland. This article is an open access article distributed under the terms and conditions of the Creative Commons Attribution (CC-BY) license (http://creativecommons.org/licenses/by/4.0/). 